\title{
UTICAJ LIDERSTVA NA ZADOVOLJSTVO I PERFORMANSE ZAPOSLENIH U MEDIJIMA
}

\author{
Sandra Dramićanin ${ }^{1}$
}

\begin{abstract}
Abstrakt: Upravljanje ljudskim resursima je ključan element svake moderne organizacije. Preduzeća iz oblasti medija koja su na vreme uočila važnost ulaganja u ljudske resurse sada koriste benefite takvih odluka u smislu visokog rejtinga i povećanog profita. U savremenim uslovima poslovanja medija, koje karakterišu brze promene i kontinuirano uvođenje novih tehnologija, neophodno je ljudske resurse prilagoditi izazovima sa kojima se suočavaju. Cilj ovog rada je istraživanje uticaja liderstva na zadovoljstvo i performanse zaposlenih u medijima u Srbiji. Uzorak obuhvata 122 ispitanika iz različitih vrsta medija sa teritorije Srbije, a podaci su dobijeni korišćenjem online upitnika koji je sadržao 20 pitanja podeljenih u 3 kategorije. Rezultati pokazuju da liderstvo ima pozitivan i značajan uticaj na zadovoljstvo zaposlenih, dok to nije slučaj sa performansama zaposlenih u medijima. Stav i ponašanje lidera u medijskim organizacijama direktno utiče na zadovoljstvo njegovih zaposlenih, što u krajnjoj istanci ima odraz na poslovnu izvrsnost medija i mogućnost poboljšanja pozicije na medijskom tržištu. Sa druge strane liderstvo nema pozitivan i značajan uticaj na performanse zaposlenih, ali dalja istraživanja mogu ići u pravcu analize medijatorske uloge zadovoljstva zaposlenih između liderstva i performansi zaposlenih u medijima.
\end{abstract}

Ključne reči: liderstvo, zadovoljstvo zaposlenih, performanse zaposlenih, mediji

1 Fakultet za hotelijerstvo i turizam u Vrnjačkoj Banji, Univerzitet u Kragujevcu e-mail: sandradramicanin@hotmail.com 


\section{UVOD}

U prethodnih desetak godina savremene tehnologije, digitalizacija i Internet izazvali su brojne promene u društvu kada je reč o komunikaciji u svim sferama društva. Jedan od faktora koji je uticao na brojne promene jesu mediji (Čerović \& Knežević, 2019). Mediji predstavljaju način komunikacije sa širom javnošću. U savremenom društvu mediji su osnovni izvor komunikacije, pa je medijska pismenost neophodna. Mediji se razvijaju uporedo sa društvom, a na taj način i saradnja medija i društva. Temeljna uloga medija bazira se na prikupljanju, obradi i plasiranju informacija u javnost (Radović, 2019). Dok je princip rada ostao isti, vremenom su se promenile dodirne tačke sa publikom. Dostupnost i brzina širenja informacija se značajno promenila pojavom globalne raširenosti društvenih i novih medija. Masovni mediji imaju izuzetno veliki uticaj i bitnu ulogu u oblikovanju ličnih percepcija i uverenja gledalaca (Vitković, 2009). Bez obzira na to što krajnju odluku donosi najviši menadžment ili vlasnik medija, menadžment ima zadatak da kreira strategiju upravljanja programskim sadržajima, zasnovanu na kontinuitetu poslovanja medijske organizacije, ali i na nužnim inovacijama i stvaranju ubedljivih sadržaja, bez kojih ona ne može opstati na izuzetno konkurentnom medijskom tržištu (Šiđanan \& Njegovan, 2021). Masovni mediji stvaraju medijski sadržaj, poseduju specifičnu tehnološku konfiguraciju, vezani su za određenu instituciju i rade prema specifičnim zakonima, pravilima i etičkim kodeksima (Alibašić, 2019). Mediji su proizvod osoba i njihovih interesa na tržištu i prenose informacije, audio-vizuelne sadržaje različite tematike do publike shodno njihovim preferencijama (Tomić, 2017).

Upravljanje ljudskim resursima je sastavni deo svake savremene medijske organizacije i obezbeđuje potrebna znanja, veštine za rad i sposobnost rada u većim organizacijama u timovima. Upravljanje ljudskim resursima u medijima je važno kako bi se stvorilo podsticajno okruženje za sticanje znanja i lični razvoj (Grmuša, 2021). U sklopu upravljanja ljudskim resursima liderstvo postaje značajna tema i neophodan faktor svakog poslovnog poduhvata (Dramićanin et al., 2020). $\mathrm{U}$ modernom poslovnom ambijentu medijskih organizacija liderstvo naglašava fleksibilnost i podstiče strategijske promene. Lideri u skladu sa svojom ličnošću, obrazovanjem, prirodnom i zadacima, misijom i vizijom medijske organizacije koju vode, primenjuju različite stilove vođstva (Stadnicka et al., 2019). S obzirom da je liderstvo u centru istraživanja poslednjih godina, ovaj rad se bavi uticajem liderstva na zadovoljstvo i performanse zaposlenih u medijskim organizacijama (medijima) u Srbiji. 
Zadovoljstvo zaposlenih predstavlja stav koji zaposleni imaju prema svom poslu i on može biti pozitivan ili negativan (Robbins \& Judge, 2009). Zadovoljstvo zaposlenih se javlja kao rezultat percepcije posla i stepena podudarnosti očekivanja pojednica i organizacije za koju radi (Postrel, 1999). Zaposleni u medijima procenjuju svoj posao na osnovu faktora koje oni lično smatraju bitnim u odnosu na lične preferencije, pa tako zadovoljstvo ili nezadovoljstvo poslom utiču na ponašanje zaposlenih koje rezultuje odsustvom sa posla ili žalbe, pri čemu se donosi zaključak da zadovoljstvo poslom može da ukaže na percepciju zaposlenih i o organizacionoj kulturi preduzeća za koje rade (Sempane et al., 2002). Zadovoljstvo poslom je stav koji zaposleni oblikuju tako što uspoređuju svoje osećaje, verovanja i ponašanja (Perić et al., 2021). Zaposleni mogu biti zadovoljni jednim aspektom posla, kao npr. kolegama, a nezadovoljni drugim aspektom posla, npr. platom (Platsidou, 2010). Zaposleni provode dosta vremena na poslu i stoga je logično da većina faktora iz okruženja organizacije utiče na zadovoljstvo zaposlenih. Zadovoljstvo zaposlenih može se poboljšati kroz upravljanje organizacionim faktorima kao što su: organizacioni razvoj, sistem nagrađivanja, napredovanje i razvoj u karijeri, radno okruženje, odnosi sa menadžmentom, timski rad i drugo (Perić et al., 2019).

Ključno za pravilno upravljanje ljudskim resursima u medijskim organizacijama je da se odredi šta je zaposlenima bitno i šta ceni (materijalne stimulacije ili nemateriajne stimulacije). Ipak, neophodno je da postoji sklad između realnosti koju medijska organizacija može da pruži i očekivanja zaposlenih u vezi posla.

Performanse predstavljaju pokazatelj ispunjenosti ciljeva organizacije, odnosno kvalitet i kvantitet ostvarenja postavljenih planova za individue ili grupe zaposlenih (Schermerhorn et al., 2002). U savremenom poslovanju, koje karakterišu brze promene i velika konkurencija, medijske organizacije moraju da posvete vreme, ulože enegriju i angažuju ljudske i finansijske resurse kako bise adekvatno merile performanse. Sposobnost medijske organizacije da dostigne planirane ciljeve, poveća svoj profit, bude konkurentna na tržištu uz maksimalan udeo, u velikoj meri zavisi od organizacione strukture i liderstva. Liderstvo ima glavnu ulogu u ostvarenju željenih performansi (Quinton \& Wilson, 2016).

\section{Pregled literature}

Liderstvo je multidisciplinaran i izuzetno složen fenomen. To je proces uticaja na ljude da se angažuju u postizanju određenog cilja. Suština liderstva je realizacija potencijala ličnosti lidera i zaposlenih koje oni vode (Menken, 2012). Lider 
mora prvo biti menadžer, on mora poznavati sve funkcije menadžmenta, pa je zato nerealistično favorizovati bilo menadžera, bilo lidera. lako su funkcije lidera i menadžera komplementarne, autorka Grubić-Nešić ukazuje i na stanovišta koja još uvek potenciraju različitosti u karakteristikama ovih uloga, bazirana na premisi o menadžeru kao umu i lideru kao duši organizacije. Tako, na primer, prema Benisovoj listi specifičnih odlika menadžera i lidera, menadžer je više okrenut administriranju i delovanju prema uputstvima i procedurama, dok je lider orijentisan na ljude i inovacije. Menadžer kopira, održava i računa na kontrolu, a lider razvija i podržava poverenje. Nadalje, menadžer je orijentisan na kontrolu i kratkoročne ciljeve, dok lider neguje kreativnost i orijentisan je na dugoročne staze. Prvi podržava postojeće, satus quo stanje, drugi je kreator očima uprt u horizont (GrubićNešić, 2008).

Teorije liderstva podrazumevaju određeni stil vođenja, koji obuhvata niz usklađenih aktivnosti i postupaka. Lideri u skladu sa svojom ličnošću, obrazovanjem, ali i prirodom i zadacima grupe koju vode, primenjuju različite stilove rukovođenja (Northouse, 2018). Oni preuzimaju na sebe odgovornost i moralnu obavezu da se brinu o potrebama zaposlenih i da zastupaju njihove interese (Dramićanin, 2019). Veliki lideri svojom kreativnošću, energijom i snagom duha podstiču svoje sledbenike. Međutim, sama suština nalazi se u nečemu drugom: veliki lideri pokreću emocije. Uspešan lider deluje kao emocionalni vođa grupe (Heifetz, 1994). Lider je dizajner poslovnih procesa, organizacione kulture i poslovne klime u organizaciji. On je i mentor, koji usmerava saradnike u željenom pravcu, ali je i zaštitnik svojih sledbenika od spoljašnjeg okruženja (Grubić-Nešić, 2008). Predstavljajući savremene teorije liderstva, profesorka Grubić-Nešić prethodno skreće pažnju na dve dominantne orijentacije, suprotstavljene u pristupu referentnim osobinama lidera. Prema prvoj, istraživanje karakteristika lidera treba fokusirati na osobine i karakteristike ličnosti kojima se lider razlikuje u odnosu na ostale, dok se drugi pristup bazira na opserviranju ponašanja lidera, koja ga i čine liderom. I pored ovih, konceptualnih razlika, većina autora deli mišljenje da je lidere moguće klasifikovati (idealno-tipski) u grupe autoritarnih, transformacionih i harizmatičkih.

\section{Uticaj liderstva na zadovoljstvo zaposlenih}

Zaposleni, odnosno ljudski resursi imaju centralnu ulogu u medijima. Kvalitet rada zaposlenih u medijima zavisi u prvom redu, od njihovog zadovoljstva poslom. Zadovoljstvo zaposlenih, shvata se kao kombinacija psiholoških faktora 
ili faktora okruženja koji čine zaposlenog zadovoljnim svojim poslom (Pavlović \& Marković, 2014). Glavne komponente koje doprinose zadovoljstvu zaposlenih u medijima su lojalnost organizaciji, uslovi rada, beneficije, lokacija, karijera i status. Pozitivne koristi i uključenost zaposlenih u donošenje odluka u organizaciji imaju najveći efekat kada je u pitanju posvećenost zaposlenih, čak i više od novčane naknade (Ineson et al., 2013). Posvećenost zaposlenih podrazumeva snažno verovanje u ciljeve organizacije, ulaganje napora za postizanje postavljenih ciljeva i želja za članstvom u organizaciji (Porter et al., 1974).

Zaposleni i njihove potrebe koje definišu stepen njihovog zadovoljstva, sve više postaju centar pažnje lidera koji znaju da su ljudski resursi glavni faktor konkurentske prednosti u sve dinamičnijem globalnom tržištu (Strukan et al., 2014). U kontekstu liderstva i njegovog uticaja na zadovoljstvo zaposlenih, najvažnije determinante zadovoljstva poslom su interesantan i kreativan posao, dobri odnosi sa rukovodiocima i kolegama, visoka autonomija u radu i mogućnost napredovanja, kao i sigurnost posla i sposobnost pravljenja balansa između privatnog i poslovnog života (Šušnjar i Zimanji, 2005). Zaposleni koji su zadovoljni svojim poslom imaju tendenciju da budu produktivniji, pozitivniji i kreativniji (Kong et al., 2018). Kvalitet odnosa lider-zaposleni ima veliki uticaj na i zadovoljstvo poslom (Long et al., 2014). Liderstvo je stoga vitalni faktor u orijentaciji pozitivnog stava i zadovoljstva zaposlenih u organizaciji (van Knippenberg, 2020). Nekoliko istraživača (Quin et al., 2020; Wang et al., 2020; Meng \& Berger, 2019) navodi da postoji jaka korelacija između uloga liderstva na zadovoljstvo poslom. lako literatura o upravljanju ljudskim resursima postavlja pozitivne efekte ponašanja lidera na zadovoljstvo poslom zaposlenih, uzročna staza između liderstva i zadovoljstva zaposlenih nije uvek jasna (An et al., 2020).

Bazirano na predhodnim istraživanjima, može se definisati sledeća hipoteza:

$H_{1}$ : Liderstvo ima pozitivan i značajan uticaj na zadovoljstvo zaposlenih.

\section{Uticaj liderstva na performanse zaposlenih}

Performanse zaposlenih se obično definišu kao ponašanje koje pokazuje zaposleni, dok obavlja određeni zadatak koji mu je dodelio poslodavac (Ouekouak et al., 2013). Takođe se odnosi na ishod koji je proizveo određeni poslodavac u organizaciji (Kalogiannidis, 2020). Performanse zaposlenih su povezane sa dostignućima svakog zaposlenog u skladu sa različitim pravilima, propisima ili očekivanjima organizacije ili lidera (Fuertes et al., 2020). Performanse zaposlenih odražavaju sposobnosti svakog pojedinačnog zaposlenog u organizaciji (Kovačević, 
2021). Većina kompetentnih i iskusnih zaposlenih ima tendenciju da pokaže visok nivo stručnosti i posvećenosti na poslu što dovodi do većeg učinka zaposlenih u poređenju sa onima sa manje stručnosti i veština (Jiang et al., 2020).

Sposobnost organizacije da dostigne planirane ciljeve, poveća profit, bude konkurentna i poveća svoj udeo na tržištu zavisi od organizacione strategije. A uspešne organizacije procenjuju svoje i performanse svojih zaposlenih i mere njihovo napredovanje pod različitim vrstama uticaja (liderstvo, motivacija, zadovoljstvo zaposlenih...)(Parveen et al., 2015). Merenje napredovanja organizacije i njenih zaposlenih može biti finansijske i nefinansijske prirode. Cilj medijskih organizacija nije samo povećanje profita, već i unapređenje poslovanja kroz poboljšanje drugih performansi (na primer kod zaposlenih) (Terek, 2016).

Liderstvo ima glavnu ulogu u ostvarenju željenih performansi kako organizacije, tako i zaposlenih (Iskamto, 2021). Ipak, pojedina istraživanja pokazuju da ne postoji uticaj liderstva na performanse zaposlenih (Meslec et al., 2020; Paais \& Pattiruhu, 2020; Braun et al., 2013). Dok kod drugih postoji pozitivna veza između liderstva i performansi (Torlak et al., 2021; Lee, 2020).

Ono što većina istraživača navodi je da između liderstva i performani zaposlenih treba da postoji medijatorska varijabla i u najvećem broju istraživanja, to je zadovoljstvo zaposlenih (Paais \& Pattiruhu, 2020; Zaim et al., 2020; Eliyana etr al., 2019; Chiniara \& Bentein, 2016).

Bazirano na predhodnim istraživanjima, može se definisati sledeća hipoteza: $\mathrm{H}_{2}$ : Liderstvo ima pozitivan i značajan uticaj na performanse zaposlenih.

\section{METOD ISTRAŽIVANJA}

\section{Uzorak}

Uzorak istraživanja predstavljaju 122 ispitanika iz različitih vrsta medija (televizija, radio, novine, časopisi, online mediji) sa teritorije Republike Srbije, od toga je 80 zaposlenih na neodređeno vreme, a 42 zaposlenih na određeno vreme. Istraživanje je izvršeno u periodu od jula do novembra 2021. godine.

\section{Materijal}

Za ovo istraživanje korišćena je anketa konstruisana od strane autora Paais \& Pattiruhu (2020), koja je sadržala 20 pitanja u 3 kategorije: liderstvo (6), zadovolj- 
stvo zaposlenih (7) i performanse zaposlenih (7). Pored toga ispitanici su odgovarali na opšta demografska pitanja (pol, godine starosti, godine radnog staža u medijima, vrsta ugovora (određeno ili neodređeno), vrsta medija u kojima rade). Za dobijanje rezultata korišćen je SPSS 20, Pirsonov koeficijent korelacije i Faktorska analiza. Nakon transformacije odgovora u numeričke vrednosti, hipoteze su testirane korelacionim metodom sa sa značajnošću $(p<0,05)$ i Faktorskom analizom.

\section{REZULTATI I DISKUSIJA}

\section{Rezultati}

Demografske karakteristike ispitanika nalaze se u Tabeli 1.

Tabela 1. Demografske karakteristike ispitanika

\begin{tabular}{|cccc|}
\hline Demografske karakteristike & Odgovor & Broj & Procenat \\
\hline \multirow{2}{*}{ Pol } & Muški & 76 & $62 \%$ \\
& Ženski & 46 & $38 \%$ \\
\hline \multirow{3}{*}{ Godine starosti } & $18-25$ & 24 & $20 \%$ \\
& $26-35$ & 36 & $30 \%$ \\
& $36-45$ & 28 & $23 \%$ \\
& $46-55$ & 23 & $19 \%$ \\
Godine radnog staža u medijima & Više od 55 & 11 & $9 \%$ \\
& $0-5$ & 35 & $29 \%$ \\
& $6-10$ & 41 & $34 \%$ \\
& $11-20$ & 26 & $21 \%$ \\
& Preko 20 & 20 & $16 \%$ \\
\hline \multirow{2}{*}{ Vrsta ugovora } & Nedređeno & 80 & $66 \%$ \\
& Određeno & 42 & $34 \%$ \\
\hline \multirow{2}{*}{ Vrsta medija } & Televizija & 27 & $22 \%$ \\
& Radio & 28 & $23 \%$ \\
& Novine & 15 & $12 \%$ \\
& Časopisi & 10 & $8 \%$ \\
& Online mediji & 42 & $34 \%$ \\
\hline
\end{tabular}


Prema demografskim karakteristikama većina ispitanika je muškog pola, ima između 26-35 godina, radni staž u medijima je između 6 i 10 godina, zaposleni su na neodređeno i rade $u$ online medijima.

Konceptualni okvir predstavljen je na Slici 1. shodno postavljenim hipotezama.

Slika 1. Konceptualni okvir istraživanja

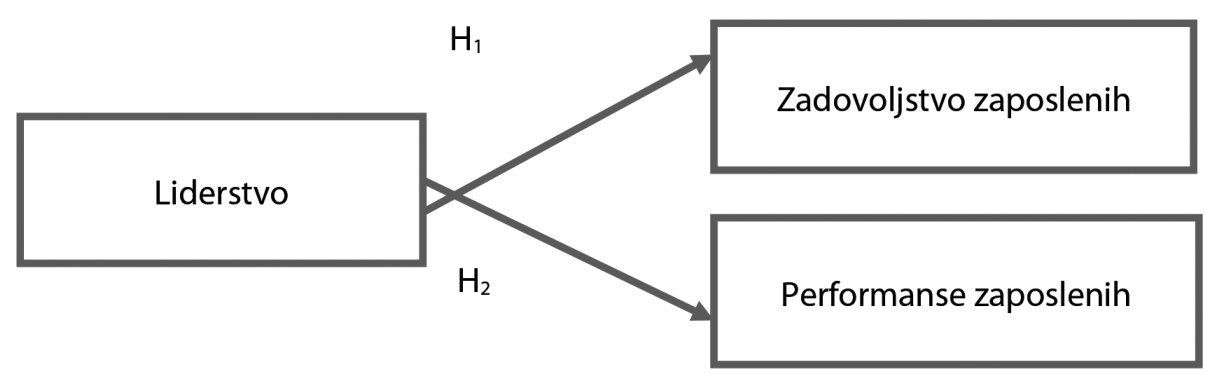

Prvenstveno je ispitivana validnost istraživačkih varijabli, koje su objašnjene vrednostima kritičnog odnosa (C.R- Critical tratio) i procenjene vrednosti (Procena), a potom se vrši upoređivanje se standardnom vrednošću greške (S.E.- Standard Error Value).

Najdominantnija stavka za Liderstvo je L6 (procena $=1.206$, S.E. $=0.174$ i C.R. $=8.880$ ), za Zadovoljstvo zaposlenih stavka Z2 (procena $=1.260$, S.E. $=0.184$ i C.R. $=10.160)$ i za Performanse zaposlenih P6 (procena $=1.220$, S.E. $=0.110$ i C.R. $=$ 10.452).

Tabela 2. Faktorska analiza

\begin{tabular}{llccccc}
\hline & Varijabla & Relativ. & Procena & S.E. & C.R. & Rezultat \\
\hline L1 & Liderstvo & 0.624 & 1.060 & 0.182 & 8.206 & Validan \\
L2 & Liderstvo & 0.704 & 1.210 & 0.166 & 8.138 & Validan \\
L3 & Liderstvo & 0.604 & 1.080 & 0.178 & 7.640 & Validan \\
L4 & Liderstvo & 0.722 & 1.110 & 0.172 & 8.136 & Validan \\
L5 & Liderstvo & 0.694 & 0.990 & 0.166 & 7.890 & Validan \\
L6 & Liderstvo & $\mathbf{0 . 7 6 6}$ & 1.206 & 0.174 & 8.880 & Validan \\
Z1 & Zadovoljstvo zaposlenih & 0.806 & 1.140 & 0.126 & 9.980 & Validan
\end{tabular}




\begin{tabular}{lllllll} 
Z2 & Zadovoljstvo zaposlenih & $\mathbf{0 . 8 1 2}$ & 1.260 & 0.184 & 10.160 & Validan \\
\hline Z3 & Zadovoljstvo zaposlenih & 0.798 & 1.262 & 0.176 & 10.980 & Validan \\
Z4 & Zadovoljstvo zaposlenih & 0.718 & 1.164 & 0.120 & 10.860 & Validan \\
Z5 & Zadovoljstvo zaposlenih & 0.745 & 0.960 & 0.138 & 11.010 & Validan \\
Z6 & Zadovoljstvo zaposlenih & 0.808 & 0.890 & 0.120 & 11.250 & Validan \\
Z7 & Zadovoljstvo zaposlenih & 0.796 & 1.038 & 0.090 & 11.358 & Validan \\
P1 & Performanse zaposlenih & 0.742 & 1.030 & 0.176 & 9.560 & Validan \\
P2 & Performanse zaposlenih & 0.718 & 1.075 & 0.088 & 10.680 & Validan \\
P3 & Performanse zaposlenih & 0.792 & 1.120 & 0.106 & 9.486 & Validan \\
P4 & Performanse zaposlenih & 0.748 & 0.998 & 0.108 & 9.872 & Validan \\
P5 & Performanse zaposlenih & 0.726 & 0.930 & 0.100 & 9.868 & Validan \\
P6 & Performanse zaposlenih & $\mathbf{0 . 8 3 0}$ & 1.220 & 0.110 & 10.452 & Validan \\
P7 & Performanse zaposlenih & 0.812 & 1.202 & 0.980 & 10.210 & Validan \\
\hline
\end{tabular}

Sveukupno merene vrednosti se deklarišu kao validne i pouzdane.

Testiranje hipoteza iz Tabele 3 pokazuje da su od dve hipoteze jedna potvrđena $\left(\mathrm{H}_{1}\right)$, a druga nije $\left(\mathrm{H}_{2}\right)$.

Tabela 3. Testiranje hipoteza

\begin{tabular}{ccccc}
\hline & Hipoteza & $p$-vrednost & Informacija & Rezultat \\
\hline $\mathrm{H}_{1}$ & Liderstvo Zadovoljstvo & 0.005 & $\begin{array}{c}\text { Pozitivna i } \\
\text { značajna }\end{array}$ & Potvrđena \\
$\mathrm{H}_{2}$ & Liderstvo Performanse & 0.000 & $\begin{array}{c}\text { Negativna i } \\
\text { nije značajna }\end{array}$ & Opovrgnuta \\
\hline
\end{tabular}

\section{DISKUSIJA}

Liderstvo predstavlja sposobnost usmeravanja i mobilisanja ljudskih resursa, kao i uticaj na zaposlene da obavljaju zadatke u sklopu radnih procesa (Nguyen et al., 2019). Za lidere je neophodno da poznaju način na koji funkcionišu njihovi zaposleni, kako bi u rukoviđenju mogli da primene određene obrasce i usmere zaposlene na aktivnosti na takav način da to podstiče njihovo zadovoljstvo (Meng \& Berger, 2019). Rezultati ovog istraživanja su pokazali da liderstvo ima pozitivan i značajan uticaj na zadovoljstvo zaposlenih u medijskim organizacijama. Do istih rezultata kada se govori o uticaju liderstva na zadovoljstvo zaposlenih došli su i 
drugi istraživači (An et al., 2020; van Knippenberg, 2020; Quin et al., 2020; Wang et al., 2020; Eliyana et al., 2019; Kammerhoff et al., 2019; Meng \& Berger, 2019; Long et al., 2014; Mujkić et al., 2014; Madlock, 2008; Berson \& Linton, 2005).

Liderstvo se definiše i kao sposobnost korišćenja menadžerskih kompetencija kako bi se organizovali procesi na taj način što se zaposleni inspirišu i motivišu da ispune postavljene ciljeve, a na taj način se utiče na njihove performanse (Buil, 2019). Rezultati ovog istraživanja su pokazali da ne postoji pozitivna i značajna veza između liderstva i performansi zaposlenih. Do istih rezultata su došli i drugi istraživači (Meslec et al., 2020; Paais \& Pattiruhu, 2020; Chen et al., 2014; Braun et al., 2013). Ipak, postoje istraživanja kod kojih postoji pozitivna veza koja je značajna između liderstva i performansi zaposlenih. Autori navode da je radi o određenim stilovima liderstva i da nije primenjljivo kod svih stilova (Torlak et al., 2021; Lee, 2020; Walumbwa et al., 2011).

Odgovarajući stilovi rukovođenja i zadovoljstvo poslom su faktori koji doprinose tome utvrđeno je da je od suštinskog značaja za organizacione performanse (Herold, 2007). Ono što većina istraživača navodi je da između liderstva i performani zaposlenih treba da postoji medijatorska varijabla i u najvećem broju istraživanja, to je zadovoljstvo zaposlenih (Paais \& Pattiruhu, 2020; Thanh et al., 2020; Zaim et al., 2020; Eliyana etr al., 2019; Chiniara \& Bentein, 2016; lqbal et al., 2015; Paracha et al., 2012).

\section{ZAKLJUČAK}

Ovo istraživanje se bavilo analizom uticaja liderstva na zadovoljstvo zaposlenih i performanse zaposlenih u medijskim organizacijama u Srbiji. Rezultati istraživanja su pokazali da liderstvo ima pozitivan i značajan uticaj na zadovoljstvo zaposlenih koji rade u medijima, dok liderstvo nema pozitivan ni značajan uticaj na performanse zaposlenih u medijima. Istraživanje ostavlja mogućnosti za dalju analizu, konkretno u smeru medijatorske uloge zadovoljstva zaposlenih između liderstva i performansi, kao i analizu uticaja različitih stilova liderstva na zadovoljstvo i performanse. Buduća istraživanja mogu da uvedu i motivaciju kao medijatorsku varijablu na relaciji liderstvo-zadovoljstvo i liderstvo-performanse zaposlenih. 


\section{LITERATURA}

1. Alibašić, H. (2019). Utjecaj savremenih medija na tokove globalizacije u 21. stoljeću. DHS-Društvene i humanističke studije: časopis Filozofskog fakulteta u Tuzli, 9(9), 345-360.

2. An, S. H., Meier, K. J., Ladenburg, J., \& Westergård-Nielsen, N. (2020). Leadership and job satisfaction: Addressing endogeneity with panel data from a field experiment. Review of Public Personnel Administration, 40(4), 589-612.

3. Berson, Y., \& Linton, J. D. (2005). An examination of the relationships between leadership style, quality, and employee satisfaction in R\&D versus administrative environments. R\&D Management, 35(1), 51-60.

4. Braun, S., Peus, C., Weisweiler, S., \& Frey, D. (2013). Transformational leadership, job satisfaction, and team performance: A multilevel mediation model of trust. The Leadership Quarterly, 24(1), 270-283.

5. Buil, I., Martínez, E., \& Matute, J. (2019). Transformational leadership and employee performance: The role of identification, engagement and proactive personality. International Journal of Hospitality Management, 77, 64-75.

6. Chen, X. P., Eberly, M. B., Chiang, T. J., Farh, J. L., \& Cheng, B. S. (2014). Affective trust in Chinese leaders: Linking paternalistic leadership to employee performance. Journal of management, 40(3), 796-819.

7. Chiniara, M., \& Bentein, K. (2016). Linking servant leadership to individual performance: Differentiating the mediating role of autonomy, competence and relatedness need satisfaction. Leadership Quarterly, 27(1), 124-141.

8. Čerović, S., \& Knežević, M. (2019). Menadžment u hotelijerstvu. Beograd: Univerzitet Singidunum.

9. Dramićanin, S. (2019). The impact of authentic leadership on the commitment of employees in travel agencies in the Republic of Serbia. Bizinfo (Blace), 10(1), 29-41.

10. Eliyana, A., Ma'arif, S., \& Muzakki. (2019). Job satisfaction and organizational commitment effect in the transformational leadership towards employee performance. European Research on Management and Business Economics, 25(3), 144-150.

11. Fuertes, G., Alfaro, M., Vargas, E., Lillo, S., Ternero, R., \& Sabattin, J. (2020). Conceptual Framework for the Strategic Management: A Literature Review-Descriptive. Journal of Engineering, 7, 1-21.

12. Grmuša, T. (2021). Učinci digitalne transformacije na inovativnost medijskih organizacija i novi poslovni modeli. Medijska agenda, 71-88.

13. Grubić-Nešić, L. (2008). Knowing how to be a leader. Novi Sad: AB print. 
14. Heifetz, R. A. (1994). Leadership without easy answers. Cambridge: Harvard University Press.

15. Ineson, E. M., Benke, E., \& Laszlo, J. (2013). Employee loyalty in Hungarian hotels. International Journal of Hospitality Management, 32, 31-39.

16. Iqbal, N., Anwar, S., \& Haider, N. (2015). Effect of leadership style on employee performance. Arabian Journal of Business and Management Review, 5(5), 1-6.

17. Iskamto, D., Srimulatsih, M., Ansori, P. B., Ghazali, P. L., Foziah, N. H. M., Arifin, J., \& Bon, A. T. (2021). Analysis of Relationship between Leadership and Employee Performance at Manufactur Company in Indoenesia. In Proceedings of the 11th Annual International Conference on Industrial Engineering and Operations Management. Singapore: IEOM Society International, 8, 3262-3269.

18. Jiang, X., Du, J., Zhou, J., \& Cui, Y. (2020). The impact of negative informal information before a change on performance: A within-person approach. International journal of environmental research and public health, 17(2), 670.

19. Kalogiannidis, S. (2020). Impact of Effective Business Communication on Employee Performance. European Journal of Business and Management Research, 5(6), 1-6.

20. Kammerhoff, J., Lauenstein, O., \& Schütz, A. (2019). Leading toward harmony - Different types of conflict mediate how followers' perceptions of transformational leadership are related to job satisfaction and performance. European Management Journal, $37(2), 210-221$.

21. Kong, H., Jiang, X., Chan, W., \& Zhou, X. (2018). Job satisfaction research in the field of hospitality and tourism. International Journal of Contemporary Hospitality Management, 30(5), 2178-2194.

22. Kovačević, B. (2021). Teorijske osnove koncepta upravljanja performancama. Ekonbiz, 20, 65-74.

23. Lee, H. W. (2020). Motivational effect of performance management: does leadership matter?. Transylvanian Review of Administrative Sciences, 16(59), 59-76.

24. Long, C. S., Yusof, W. M. M., Kowang, T. O., \& Heng, L. H. (2014). The impact of transformational leadership style on job satisfaction. World Applied Sciences Journal, 29(1), 117-124.

25. Madlock, P. E. (2008). The link between leadership style, communicator competence, and employee satisfaction. The Journal of Business Communication, 45(1), 61-78.

26. Meng, J., \& Berger, B. K. (2019). The impact of organizational culture and leadership performance on PR professionals' job satisfaction: Testing the joint mediating effects of engagement and trust. Public Relations Review, 45(1), 64-75.

27. Menken, J. (2012). What All Great Leaders Have. New York: Executive Intelligence. 
28. Meslec, N., Curseu, P. L., Fodor, O. C., \& Kenda, R. (2020). Effects of charismatic leadership and rewards on individual performance. The Leadership Quarterly, 31(6), 101423.

29. Mujkić, A., Šehić, D., Rahimić, Z., \& Jusić, J. (2014). Transformational leadership and employee satisfaction. Ekonomski vjesnik: Review of Contemporary Entrepreneurship, Business, and Economic Issues, 27(2), 259-270.

30. Nguyen, H. M., Mai, L. T., \& Huynh, T. L. (2019). The Role of Transformational Leadership toward Work Performance through Intrinsic Motivation: A Study in the Pharmaceutical Field in Vietnam. Journal of Asian Finance, Economics and Business, 6(4), 201-212.

31. Northouse, P. G. (2018). Leadership: Theory and practice. Thousand Oaks: Sage publications.

32. Ouekouak, M.L., Ouedraogo, N. \& Mbengue, A. (2013). The mediating role of organizational capabilities in the relationship between middle managers' involvement and firm performance: a European study. European Management Journal, 32(2), 305- 318.

33. Parveen, F., Jaafar., N.I:, \& Ainin, S. (2016). Social media's impact on organizational performance and entrepreneurial orientation in organizations. Management Decision, 54(9), 2008-2234.

34. Pavlović, M. i Marković, D. (2014). Teorijski pristup zadovoljstvu poslom i motivaciji zaposlenih. Vojno delo, 66(1), 289-302.

35. Paracha, M. U., Qamar, A., Mirza, A., Hassan, I. U., \& Waqas, H. (2012). Impact of leadership style (transformational \& transactional leadership) on employee performance \& mediating role of job satisfaction. Study of private school (educator) in Pakistan. Global Journal of Management and Business Research, 12(4), 55-64.

36. Perić, G., Dramićanin, S., \& Pavlović, N. (2021). The influence of internal service quality and employee satisfaction on organizational commitment in travel agencies: The case of Serbia. Hotel and Tourism Management, 9(1), 43-60.

37. Perić, G., Dramićanin, S., \& Sančanin, B. (2019). Employee satisfaction in hotel industry: The case of hotel Radan in Prolom Banja. BizInfo (Blace) Journal of Economics, Management and Informatics, 10(2), 25-41.

38. Platsidou, M. (2010). School Psychology International. Trait emotional intelligence of Greek special education teachers in relation to burn out and job satisfaction, 31(1), 60-76.

39. Postrel, V. (1999). The future and its enemies. New York: Free Press.

40. Qing, M., Asif, M., Hussain, A., \& Jameel, A. (2020). Exploring the impact of ethical leadership on job satisfaction and organizational commitment in public sector organizations: The mediating role of psychological empowerment. Review of Managerial Science, 14(6), 1405-1432.

41. Quinton, S. \& Wilson, D. (2016). Tension and ties in social media networks: Towards a model of understanding business relationship development and business perfor- 
mance enhancement through the use of Linkedln. Industrial Marketing Management, $54,15-24$.

42. Radović, N. (2019). Uloga medijske konvergencije u razvoju kulturnih i kreativnih industrija. In Sinteza 2019-International Scientific Conference on Information Technology and Data Related Research (pp. 141-146). Singidunum University.

43. Robbins, S.P. \& Judge, T.A. (2009). Organizaciono ponašanje, 12th Edition. Zagreb: Mate d.o.o.

44. Schermerhorn, J.R., Hunt, J.M.,\& Osborn, R. N. (2002). Organizational Behavior, 7th Edition. New York: Wiley.

45. Sempane, M.E., Rieger, H.S. \& Roodt, G. (2002). Job Satisfaction In Relation To Organisational Culture. Journal of Industrial Psychology, 28(2), 23-30.

46. Stadnicka, D., Litwin, P., \& Antonelli, D. (2019). Human factor in industry of the future: Knowledge acquisition and motivation. FME Transactions, 47(4), 823-830.

47. Strukan, E., Đorđević, D. i Sefić, S. (2014). Uticaj liderstva na zadovoljstvo poslom u privatnom sektoru. Anali poslovne ekonomije, 11, 46-59.

48. Šiđanin, I., \& Njegovan, B. R. (2021). Upravljanje programskim sadržajem i uloga programskog menadžmenta.20thInternational Symposium INFOTEH-JAHORINA, 17-19 March 2021, 205-210

49. Šušnjar G. i Zimanji V. (2005). Organizaciono ponašanje. Subotica: Ekonomski fakultet Subotica.

50. Thanh, T., Doan, T., Cam, L., Nguyen, T., Dan, T., \& Nguyen, N. (2020). Emotional Intelligence and Project Success. The Roles of Transformational Leadership and Organizational Commitment, 7(3), 223-233.

51. Tomić, B. (2017). Nove medijske tehnologije i reformski procesi masmedija. Politeia, 7(13), 72-83.

52. Torlak, N. G., Demir, A., \& Budur, T. (2021). Decision-making, leadership and performance links in private education institutes. Rajagiri Management Journal, 15(1), 1-23.

53. Van Knippenberg, D. (2020). Meaning-based leadership. Organisational Psychology Review, 10(1), 6-28.

54. Vitković, B. (2009). Preopterećenje informacijama: kako naći relevantne informacije. CM Komunikacija i mediji, 4(12), 87-113.

55. Walumbwa, F. O., Mayer, D. M., Wang, P., Wang, H., Workman, K., \& Christensen, A. L. (2011). Linking ethical leadership to employee performance: The roles of leadermember exchange, self-efficacy, and organizational identification. Organizational behavior and human decision processes, 115(2), 204-213. 
56. Wong, C., Walsh, E. J., Basacco, K. N., Domingues, M. C. M., \& Pye, D. R. (2020). Authentic leadership and job satisfaction among long-term care nurses. Leadership in Health Services, 33(31), 247-263.

57. Zaim, H., Demir, A. \& Budur, T. (2020), Ethical leadership, effectiveness and team performance: an Islamic perspective. Middle East Journal of Management, 8(1), 42-66.

Tabela 4. Merenje varijabli

Varijabla Pitanje

\begin{tabular}{ll}
\hline & L1: Pravac u kojem se moja organizacija kreće je pouzdan \\
& L2: Lider uvek poziva zaposlene na razgovor, posebno ako se pitanja \\
odnose na njih direktno \\
L3: Lider je poštena osoba \\
L4: Lider se odnosi profeisonalno prema zaposlenima i razlikuje lična i \\
profesionalna pitanja \\
L5: Lider dozvoljava da se posao obavi na kreativan način, sve dok ne \\
narušava pravila organizacije \\
L6: Lider uvek razmišlja o interesima zaposlenih
\end{tabular}

$\begin{array}{ll} & \text { Z1: Postoji balans između društvenog života i posla } \\ & \text { Z2: Osećam ponos zato što radim u ovoj organizaciji } \\ \text { Zadovoljstvo } & \text { Z3: Osećam se motivisano da nastavima da radim aktivno } \\ \text { zaposlenih } & \text { Z4: Organizacija inspiriše mene i tim } \\ & \text { Z5: Osećam zadovoljstvo kada radim sa kolegama u ovoj organizaciji } \\ & \text { Z6: Organizacija razmatra sve sugestije i žalbe zaposlenih } \\ & \text { Z7: Menadžment podržava razvoj karijere zaposlenih }\end{array}$

P1: Postoje stroga pravila i propisi kojih zaposleni moraju da se pridržavaju

P2: Sistem nagrađivanja je profesionalan i transparentan

Performanse

P3: Organizacija nagrađuje zaposlene koji su ostvarili zadate ciljeve zaposlenih

P4: Obuka i razvoj motivišu zaposlene da rade optimalno

P5: Zaposleni redovno dolaze na posao (nema izostanaka)

P6: Postavljeni ciljevi organizacije su uvek dostignuti ili čak premašeni

P7: Povećanje vrednosti imovine i dobre korporativne investicije se vide kroz finansijske izveštaje i organizacija profitira 